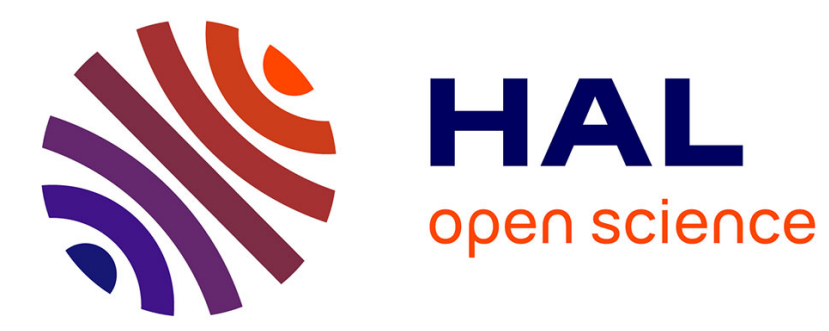

\title{
Tenascin- $X$ increases the stiffness of collagen gels without affecting fibrillogenesis
}

Yoran Margaron, Luciana Bostan, Jean-Yves Exposito, Maryline Malbouyres, Ana-Maria Trunfio-Sfarghiu, Yves Berthier, Claire Lethias

\section{- To cite this version:}

Yoran Margaron, Luciana Bostan, Jean-Yves Exposito, Maryline Malbouyres, Ana-Maria TrunfioSfarghiu, et al.. Tenascin-X increases the stiffness of collagen gels without affecting fibrillogenesis. Biophysical Chemistry, 2010, 147 (1-2), pp.87. 10.1016/j.bpc.2009.12.011 . hal-00612709

\section{HAL Id: hal-00612709 https://hal.science/hal-00612709}

Submitted on 30 Jul 2011

HAL is a multi-disciplinary open access archive for the deposit and dissemination of scientific research documents, whether they are published or not. The documents may come from teaching and research institutions in France or abroad, or from public or private research centers.
L'archive ouverte pluridisciplinaire HAL, est destinée au dépôt et à la diffusion de documents scientifiques de niveau recherche, publiés ou non, émanant des établissements d'enseignement et de recherche français ou étrangers, des laboratoires publics ou privés. 


\section{Accepted Manuscript}

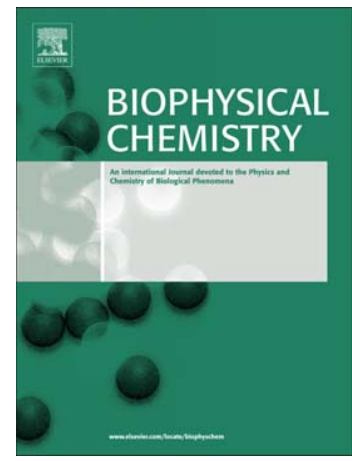

Tenascin-X increases the stiffness of collagen gels without affecting fibrillogenesis

Yoran Margaron, Luciana Bostan, Jean-Yves Exposito, Maryline Malbouyres, Ana-Maria Trunfio-Sfarghiu, Yves Berthier, Claire Lethias

PII: $\quad$ S0301-4622(09)00256-7

DOI: $\quad$ doi: $10.1016 /$ j.bpc.2009.12.011

Reference: $\quad$ BIOCHE 5329

To appear in: Biophysical Chemistry

Received date: $\quad 10$ November 2009

Revised date: 23 December 2009

Accepted date: 27 December 2009

Please cite this article as: Yoran Margaron, Luciana Bostan, Jean-Yves Exposito, Maryline Malbouyres, Ana-Maria Trunfio-Sfarghiu, Yves Berthier, Claire Lethias, Tenascin-X increases the stiffness of collagen gels without affecting fibrillogenesis, Biophysical Chemistry (2010), doi: 10.1016/j.bpc.2009.12.011

This is a PDF file of an unedited manuscript that has been accepted for publication. As a service to our customers we are providing this early version of the manuscript. The manuscript will undergo copyediting, typesetting, and review of the resulting proof before it is published in its final form. Please note that during the production process errors may be discovered which could affect the content, and all legal disclaimers that apply to the journal pertain. 
Tenascin- $\mathrm{X}$ increases the stiffness of collagen gels without affecting fibrillogenesis

Yoran Margaron ${ }^{1}$, Luciana Bostan ${ }^{2,3}$, Jean-Yves Exposito ${ }^{1}$, Maryline Malbouyres ${ }^{1}$, AnaMaria Trunfio-Sfarghiu ${ }^{2}$, Yves Berthier ${ }^{2}$ and Claire Lethias ${ }^{1}$,

${ }^{1}$ Institut de Biologie et Chimie des Protéines, IFR 128 Biosciences Lyon-Gerland, CNRS UMR 5086, Université de Lyon, 7 passage du Vercors, F-69367 Lyon Cedex 07, France.

${ }^{2}$ Université de Lyon, CNRS INSA-Lyon, LaMCoS UMR5259, F-69621 Villeurbanne Cedex, France.

3 The "Gh. Asachi" Technical University of Iasi, Faculty of Chemical Engineering and Environmental Protection, Bd Mangeron, 71A, 700050, Iasi, Romania.

\section{ABSTRACT}

Tenascin- $\mathrm{X}$ is an extracellular matrix protein whose absence leads to an Ehlers-Danlos Syndrome in humans, mainly characterised by connective tissue defects including the disorganisation of fibrillar networks, a reduced collagen deposition, and modifications in the mechanical properties of dense tissues. Here we tested the effect of tenascin-X on in vitro collagen fibril formation. We observed that the main parameters of fibrillogenesis were unchanged, and that the diameter of fibrils was not significantly different when they were formed in the presence of tenascin-X. Interestingly, mechanical analysis of collagen gels showed an increased compressive resistance of the gels containing tenascin-X, indicating that this protein might be directly involved in determinating the mechanical properties of collagen-rich tissues in vivo.

Key words: extracellular matrix, Ehlers-Danlos Syndrome, tenascin-X, collagen, elastic modulus.

\footnotetext{
${ }^{1}$ Corresponding author

Phone: (33) 4727226 53, Fax: (33) 4727226 04, e-mail: c.lethias@ibcp.fr
} 


\section{INTRODUCTION}

Tenascin-X (TNX) is a huge extracellular matrix glycoprotein that has a multidomain structure consisting of an $\mathrm{N}$-terminal region involved in oligomerisation, a series of epidermal growth factor (EGF)-like repeats, a variable number of fibronectin-type III (FNIII) modules and a C-terminal domain homologous to fibrinogen (Fbg) [1]. Several observations suggest that TNX is involved in the deposition and/or stabilisation of collagen fibrils, and in influencing the mechanical properties of connective tissues. Indeed, TNX deficiency leads to the appearance of an Ehlers-Danlos Syndrome in humans [2]. Major clinical symptoms consist of skin hyperextensibility and joint laxity, while ultrastructural analyses reveal abnormalities in collagen fibril networks and elastic fibre morphology. Mice deficient in TNX partly reproduced this phenotype [3], and fibroblasts isolated from these mice failed to deposit collagen in cell culture [4]. Moreover, we have previously demonstrated that TNX is localised at the surface of collagen fibrils within tissues [5]. This association might be explained by the interaction of TNX with several molecular components of these fibrils i.e. decorin, fibrillar and FACIT collagens $[6,7,8]$. More recently, it was shown that TNX has elastic properties, due to the extension/refolding of its constitutive FNIII modules [9]. Taken together, these data suggest that TNX might affect collagen fibrillogenesis and/or act as a bridge between collagen fibrils and consequently modulate the mechanical properties of connective tissues. In order to test these hypotheses, we analysed the consequences of TNX-collagen interaction in vitro, by studying the influence of TNX on collagen fibrillogenesis, and by measuring the mechanical properties of collagen gels polymerised in the presence of TNX. 


\section{MATERIALS AND METHODS}

\subsection{Production and purification of recombinant TNX}

Recombinant full length bovine TNX was produced in mammalian HEK293 cells as previously described $[7,10]$. TNX was further purified from the culture medium by two chromatographic steps: firstly on heparin-Sepharose (GE Healthcare), and secondly on Q-Sepharose (GE Healthcare) [7]. TNX fractions were dialyzed against phosphate-buffered saline (PBS) and stored at $-80^{\circ} \mathrm{C}$. Protein concentration was determined using the QuantiPro BCA assay kit (Sigma) according to the manufacturer's instructions.

\subsection{Preparation of acid-soluble collagen}

Acid-soluble collagen was extracted from tail tendons of young rats using standard procedures. All steps were performed at $4^{\circ} \mathrm{C}$. Tendons were dissected in $0.2 \mathrm{M} \mathrm{NaCl}$, then dilacerated and transferred to $0.5 \mathrm{M}$ acetic acid/ $0.2 \mathrm{M} \mathrm{NaCl}$ for $48 \mathrm{~h}$. The extract was centrifuged at $20,000 \mathrm{~g}$ for $20 \mathrm{~min}$, and the resulting supernatant was dialysed against $0.5 \mathrm{M}$ acetic acid/0.9 M NaCl. After centrifugation (20,000 g, $20 \mathrm{~min}$ ), the pellet was treated with $70 \%$ ethanol, dried in a sterile atmosphere, and dissolved in $0.001 \mathrm{M} \mathrm{HCl}$. Collagen concentration was determined by both QuantiPro BCA assay kit and amino-acid analysis.

\subsection{Collagen fibrillogenesis assays}

Collagen solutions ( 3 to $5.6 \mathrm{mg} / \mathrm{mL}$ ) were neutralised on ice using $0.5 \mathrm{M} \mathrm{NaOH}$ and diluted to a final concentration of $1 \mathrm{mg} / \mathrm{mL}$ by the addition of PBS containing recombinant TNX or control protein. Fibrillogenesis was initiated by warming the solutions to $37^{\circ} \mathrm{C}$ in a thermostated cuvette, and gelation was detected by monitoring turbidity at $400 \mathrm{~nm}$ in a DU 640 spectrophotometer (Beckman). Assays were performed in triplicate and a minimum of three independent experiments were carried out. Pepsin-extracted bovine collagen was purchased from BD Biosciences (Le Pont de Claix, France).

\subsection{Scanning electron microscopy}

Collagen gels, prepared as described for the fibrillogenesis assay, were briefly rinsed in $0.15 \mathrm{M}$ sodium cacodylate (Sigma) $\mathrm{pH} 7.4$ then fixed for 1 hour in $2 \%$ glutaraldehyde (Electron Microscopy Sciences) diluted in the same buffer. After further rinsing, gels were treated for 45 min with $1 \%$ osmium tetroxide diluted in $0.1 \mathrm{M}$ sodium cacodylate. Samples 
were then dehydrated by a series of graded ethanol solutions, impregnated in hexamethyldisilazane (Sigma), and air-dried. After coating with gold-palladium by sputtering, the gels were observed with a Hitachi S800 microscope (operating at $15 \mathrm{kV}$ ) at the "Centre Technologique des Microstructures" (Université de Lyon). Collagen fibril diameters were measured using NIH Image J software.

\subsection{Mechanical tests}

Neutralised collagen solutions were prepared as described in the fibrillogenesis section, and $10.5 \mathrm{~mL}$ aliquots were transferred to $60 \mathrm{~mm}$ diameter cell culture Petri dishes (Falcon). Gelation was carried out for $30 \mathrm{~min}$ at $37^{\circ} \mathrm{C}$, then collagen gels were stored at $4{ }^{\circ} \mathrm{C}$ in the presence of PBS until mechanical testing. Collagen gel samples had a cylindrical form, with diameter $\sim 50 \mathrm{~mm}$ and height $\sim 3 \mathrm{~mm}$, and their mechanical resistance was measured by compression testing in an unconfined configuration.

Step-wise compression tests were performed with an Advanced Rheometric Expansion System (ARES) equipped with a maximum cell load of $20 \mathrm{~N}$ and controlled gap (hi) (TA Instruments). The load assembly consists of two stainless steel $50 \mathrm{~mm}$ diameter parallel plates above and below the sample. In order to control the boundary conditions, the stainless steel platens were sonicated twice for $10 \mathrm{~min}$ at $25^{\circ} \mathrm{C}$ in ethanol before use. For each test, a cycle of 4 strains was performed at an imposed speed deformation of $0.02 \mathrm{~mm} / \mathrm{s}$, the compression level representing $5 \%$ of the sample thickness. Every compression strain ramp was followed by a period of stress relaxation of $600 \mathrm{~s}$. This period of stress relaxation was necessary to reach the balance of stress equilibrium characteristic to cartilage biphasic materials [11].

The normal force and the gap thickness were directly measured by the rheometer sensors. To reproduce the same initial load condition, the test began after having submitted each sample to a compressive force of $0.02 \mathrm{~N}$ followed by a $600 \mathrm{~s}$ relaxation period. Stressrelaxation curves were generated for each sample, including compressive and relaxation stresses, calculated as normal force divided by gel area, and were drawn as a function of time. Stress-strain curves were generated for each sample by taking only into consideration the compression peak stress, where the compressive strain was calculated as (h0-hi)/h0 (where h0 is the initial gap). The linear regression slope of the stress-strain curve was used to estimate the apparent elastic modulus of each gel.

For each type of gel (collagen only, collagen and BSA, collagen and TNX), four samples were tested, and each test was repeated three times to verify the reproducibility of measurements. 


\section{RESULTS AND DISCUSSION}

\subsection{Influence of TNX on collagen fibrillogenesis}

The effect of TNX on collagen fibril formation was tested in vitro by monitoring turbidity during the gelation process. As shown in Fig. 1, TNX did not seem to affect collagen fibrillogenesis except at high concentrations where a slight delay in the initiation step was apparent. However, the same effect was obtained by the addition of a control protein (BSA), which does not specifically interact with fibrillar collagens. A careful examination of the fibrillogenesis parameters led to the same conclusion (Table I). Neither the lag phase, nor the fibrillogenesis rate or the absorbance plateau were significantly modified by the presence of TNX. These results are somehow contradictory with previous results [12] showing a diminished lag phase and an increased absorbance plateau of collagen solutions when fibrillogenesis assays were done in the presence of TNX.

The first point of divergence that might explain the discrepancy between our results and those of Minamitani et al. [12] concern the source of the collagen. Their collagen solution was from a commercial source, and gave rise to slow fibrillogenesis in control conditions ( $2 \mathrm{~h}$ for their lag phase instead of $5 \mathrm{~min}$ in our experiments and elsewhere $[13,14])$. One explanation could be that the commercial collagen was pepsinised and consequently devoid of telopeptides, which have been shown to be important for fibrillogenesis [15]. To test this hypothesis, we performed fibrillogenesis assays with bovine pepsinised collagen and indeed observed a slower fibrillogenesis. However, even in these conditions, the presence of TNX did not modify the fibrillogenesis parameters compared to the control protein BSA (data not shown).

The differences observed might also result from the concentration and presence of FNIII repeats present in the recombinant TNX used during the fibrillogenesis assays. These discrepancies seem not to be due to the lower TNX-concentrations $(0.2$ to $0.5 \mu \mathrm{g} / \mathrm{mL})$ used in Ref. 12, since we did not observe any differences in the fibrillogenesis parameters in this range of concentration (data not shown). Moreover, these authors used a small isoform lacking the central FNIII modules, whereas we produced the full-length protein comprising 30 FNIII domains. Interestingly, another group has shown that the $29^{\text {th }}$ FNIII module of TNX accelerates collagen fibrillogenesis [8], but this modulatory effect seems to be masked in 
larger constructs. Taken together, these data indicate that the modulatory effets of TNX on collagen fibrillogenesis seems to be dependent on its constitutive domains.

With the aim of determining if TNX had an influence on the morphology of the collagen fibrils, we examined the gels by scanning electron microscopy after the gelation process was completed. The resulting micrographs are shown in Fig. 2, and no striking difference was highlighted by comparison of gels formed in the presence of TNX or control proteins (BSA, fibronectin). Consistent with this observation, measurement of collagen fibril diameter distribution did not show an effect of TNX on this parameter (Fig. 3).

\subsection{Effect of TNX on the mechanical properties of collagen gels}

Considering the interaction of TNX with fibrillar collagens [7, 8] and the elastic properties of TNX [9], we decided to examine the physical behaviour of the collagen gels formed in the presence of TNX by rheometry, and to compare them to control gels consisting of collagen alone, or collagen and BSA.

The average stress-relaxation response under unconfined compression for the three types of gel is shown in Fig. 4A. The highest stress values were obtained for collagen/TNX gels while there was no obvious difference between collagen/BSA and collagen gels.

The average stress-strain response is plotted in Figs $4 \mathrm{~B}$ and $4 \mathrm{C}$, in terms of the peak compression values (PCV; Fig. 4B) or the equilibrium level values (ELV; Fig. 4C). The linear regression based on these data showed that the compressive elastic modulus of the

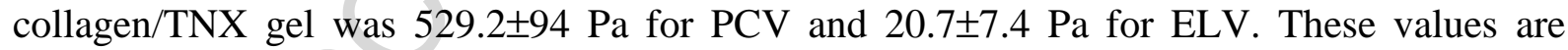
approximately twice as high as the apparent compressive elastic modulus of the collagen/BSA gel $(\mathrm{PCV}=262.1 \pm 73 \mathrm{~Pa}$ and $\mathrm{ELV}=7.8 \pm 1.6 \mathrm{~Pa})$ or the collagen gel $(\mathrm{PCV}=280.8 \pm 51 \mathrm{~Pa}$ and $E L V=8.5 \pm 2.9 \mathrm{~Pa}$ ). These values are smaller in comparison to the data obtained by Kreger and Voytik-Harbin on collagen gels [16]. This difference can be explained in two ways. The first concerns the boundary condition. In this study, the gel sample was free to slide on the stainless steel platen, which can decrease the apparent compressive elastic modulus compared to that obtained when the gel sample is fixed on the stainless steel platen. Secondly, the collagen concentration that we used is two-fold lower than in the previously published study $(1 \mathrm{mg} / \mathrm{mL}$ instead of $2 \mathrm{mg} / \mathrm{mL}$ ). In agreement with the latter explanation, it has been shown that both linear modulus and failure stress values increase linearly with collagen gel concentrations in the range 0.3 to $3 \mathrm{mg} / \mathrm{mL}$ [17]. 
The effect of TNX on the mechanical properties of collagen gels was further examined in a dose-response experiment shown in Fig. 5. The results clearly demonstrate an increase in elastic modulus correlated with an augmentation of TNX concentration. Finally, since previous experiments were performed with rat collagen combined with bovine TNX, we confirmed these results by the use of bovine collagen gels (data not shown). Firstly, values of elastic modulus in control conditions were similar to those obtained with rat collagen, and secondly, the increase in elastic modulus in the presence of TNX was of the same order of magnitude.

Thus, by these rheological studies, we can conclude that the presence of TNX within the collagen gels significantly increased their mechanical compressive behaviour, in a dosedependent manner.

\subsection{Conclusion}

As demonstrated by Mao et al. [3], TNX deficiency in mice strongly influences the mechanical properties of skin. Indeed, these authors observed an increased deformability and reduced tensile strength of this tissue in the absence of TNX. The reduced fibrillar collagen content of the tissues and the failure of fibroblasts to deposit collagen in cell cultures led to the conclusion that TNX is critical for the cell-mediated fibrillogenesis process. Our results demonstrate that TNX increases collagen gel stiffness, probably by reinforcing the association between collagen fibrils. The dose-response effect that we observed might be of significant importance in vivo since in humans, different phenotypes (classical Ehlers-Danlos Syndrome versus joint hypermobility only) are observed in patients homozygous or hetereozygous for TNX mutations, indicating a gene-dosage effect [18]. These data suggest that TNX should be involved directly in determining the mechanical properties of tissue components and might in part explain how TNX contributes to the mechanical resistance in vivo.

Acknowledgements: This work was supported by a grant from the Ligue Nationale contre le Cancer (Comité Départemental de l'Ardèche), and Y. Margaron received a $\mathrm{PhD}$ fellowship from the Ligue Nationale contre le Cancer. The authors are grateful to Dr M.C. Ronzière (IBCP, Lyon) for providing acid-soluble collagen extracted from bovine skin and to D.J.S. Hulmes for revising english. 


\section{REFERENCES}

[1] F.S. Jones and P.L. Jones, The tenascin family of ECM glycoproteins : structure, function, and regulation during embryonic development and tissue remodeling, Dev. Dyn. 218 (2000) 235-259.

[2] G.H. Burch, Y. Gong, W.H. Liu, R.W. Dettman, C.J. Curry, L. Smith, W.L. Miller, and J. Bristow, Tenascin-X deficiency is associated with Ehlers-Danlos syndrome, Nature Genet. 17 (1997) 104-108.

[3] J.R. Mao, G. Taylor, W.B. Dean, D.R. Wagner, V. Afzal, J.C. Lotz, E.M. Rubin and J. Bristow, Tenascin-X deficiency mimics Ehlers-Danlos syndrome in mice through alteration of collagen deposition, Nature Genet. 30 (2002) 421-425.

[4] J. Schalkwijk, M.C. Zweers, P.M. Steulen, W.B. Dean, G. Taylor, Y.M. van Vlijmen, B. van Haren, W.L. Miller and J. Bristow, A recessive form of the Ehlers-Danlos syndrome caused by tenascin-X deficiency, N. Engl. J. Med. 345 (2001) 1167-1175.

[5] C. Lethias, Y. Descollonges, M.M. Boutillon and R. Garrone, Flexilin : a new extracellular matrix glycoprotein localized on collagen fibrils, Matrix Biol. 15 (1996) 11-19.

[6] F. Elefteriou, J.-Y. Exposito, R. Garrone and C. Lethias, Binding of tenascin-X to decorin, FEBS Lett. 495 (2001) 44-47.

[7] C. Lethias, A. Carisey, J. Comte, C. Cluzel and J.-Y. Exposito, A model of tenascin-X integration within the collagenous network, FEBS Lett. 580 (2006) 6281-6285.

[8] D.E. Egging, F. van den Berkmortel, G. Taylor, J. Bristow and J. Schalkwijk, Interactions of human tenascin-X domains with dermal extracellular matrix molecules, Arch. Dermatol. Res. 73 (2007) 1-11.

[9] A. Jollymore, C. Lethias, Q. Peng, Y. Cao and H. Li, Nanomechanical properties of tenascin-X revealed by single-molecule force spectroscopy, J. Mol. Biol. 385 (2009) 12771286.

[10] C. Lethias, F. Elefteriou, G. Parsiegla, J.-Y. Exposito and R. Garrone, Identification and characterization of a conformational heparin-binding site involving two fibronectin type III modules of bovine tenascin-X, J. Biol. Chem. 276 (2001) 16432-16438.

[11] G.A. Ateshian, W.H. Warden, J.J. Kim, R.P. Grelsamer and V.V Mow, Finite deformation biphasic material properties of bovine articular cartilage, J. Biomech. 30 (1997) 157-1164.

[12] T. Minamitani, T. Ikuta, Y. Saito, G. Takebe, M. Sato, H. Sawa, T. Nishimura, F. Nakamura, K. Takahashi, H. Ariga and K.-I.Matsumoto, Modulation of collagen fibrillogenesis by tenascin-X and type VI collagen, Exp. Cell Res. 298 (2004) 305-315.

[13] M.M. Sullivan, T.H. Barker, S.E. Funk, A. Karchin, N.S. Seo, M. Hook, J. Sanders, B. Starcher, T.N. Wight, P. Puolakkainen and E.H. Sage, Matricellular hevin regulates decorin production and collagen assembly, J. Biol. Chem. 281 (2006) 27621-27632.

[14] C. Giudici, N. Raynal, H. Wiedemann, W.A. Cabral, J.C. Marini, R. Timpl, H.P. Bachinger, R.W. Farndale, T. Sasaki and R. Tenni, Mapping of SPARC/BM40/osteonectinbinding sites on fibrillar collagens, J. Biol. Chem. 283 (2008) 19551-19560.

[15] N. Kuznetsova and S. Leikin, Does the triple helical domain of type I collagen encode several molecular recognition and fiber assembly while telopeptides serve as catalytic domains? J. Biol. Chem. 274 (1999) 36083-36088. 
[16] S.T. Kreger and S.L. Voytik-Harbin, Hyaluronan concentration within a 3D collagen matrix modulates matrix viscoelasticity, but not fibroblast response, Matrix Biol. 28 (2009) 336-346.

[17] B.A. Roeder, K. Kokini, J.E. Sturgis, J.P. Robinson and S.L. Voytik-Harbin, Tensile mechanical properties of three-dimensional type I collagen extracellular matrices with varied microstructures, J. Biomech. Eng. 124 (2002) 214-222.

[18] M.C. Zweers, J. Bristow, P.M. Steijlen, W.B. Dean, B.C. Hamel, M. Otero, M. Kucharekova, J.B. Boezeman and J. Schalkwijk, Haploinsufficiency of TNXB is associated with hypermobility type of Ehlers-Danlos syndrome, Am. J. Hum. Genet. 73 (2003) 214-217. 


\section{FIGURE LEGENDS}

Fig. 1: Effect of TNX on collagen fibrillogenesis. Fibril formation was measured by monitoring collagen solution turbidity at $400 \mathrm{~nm}$. The different curves represent control experiment with collagen alone $(\bullet)$, collagen plus TNX at $5 \mu \mathrm{g} / \mathrm{mL}(\mathbf{\square})$ or $30 \mu \mathrm{g} / \mathrm{mL}$ (66.6 $\mathrm{nM}, \boldsymbol{\Delta})$, collagen plus BSA at $4.4 \mu \mathrm{g} / \mathrm{mL}(66.6 \mathrm{nM}, \square)$, or collagen plus fibronectin at $16.7 \mu \mathrm{g} / \mathrm{mL}(66.6 \mathrm{nM}, \diamond)$. Each point is the mean of triplicate values and error bars are SEM. The data shown are representative of three independent experiments.

Fig. 2: Morphology of collagen gels examined by Scanning Electron Microscopy. Gels formed with collagen alone (A), or in the presence of TNX (B), BSA (C) or fibronectin (D) at equimolar concentration $(66.6 \mathrm{nM})$.

Fig. 3: Fibril diameter distribution within collagen gels. Measurements were performed on scanning electron micrographs obtained from control (black bars) or TNX-containing (grey bars) gels. A minimum of two-hundred fibrils were measured for each condition. Error bars are Standard Deviation Deviation, and a statistical analysis of the fibrils diameters distribution was performed by non-parametric Mann-Whitney $U$ tests. Each sample was compared to the PBS condition.

Fig. 4: Stress-relaxation response of collagen gels. (A) Stress versus compression time curves. The purple, blue, and yellow curves correspond to collagen gels prepared in the presence of PBS, TNX $(66.6 \mathrm{nM})$ and BSA $(66.6 \mathrm{nM})$ respectively. The black curve represents the gap between the two platens. For each condition, four different samples were tested by three cycles of three successive compressions. For each type of gel, the average stress-strain response is plotted by taking into account the mean of the peak compression values (B) or of the equilibrium level values (C). The linear regression lines shown allowed the calculation of the apparent compressive elastic modulus for each gel tested. Error bars represent $\min / \max$ values values and an ANOVA test was performed as statistical analysis. Each sample was compared to PBS. ***p<0.001. 
Fig. 5: Dose-response effect of TNX on the stress-relaxation behaviour of collagen gels. Results are given as a percentage of the elastic modulus measured in the presence of $30 \mu \mathrm{g} / \mathrm{mL}$ TNX (878.18 Pa for compression peak and 15.27 Pa for equilibrium level). Error bars represent Standard Deviation and statistical analyses were performed by ANOVA. Each TNX sample was compared to the PBS condition. ${ }^{*} \mathrm{p}<0.05, * * \mathrm{p}<0.01,{ }^{*} * \mathrm{p}<0.001$. 
Table I: Collagen fibrillogenesis parameters corresponding to Fig. 1 experiments. Lag time, rate of fibrillogenesis, and absorbance plateau were calculated according to the method published by Sullivan et al. [12].

\begin{tabular}{lccc}
\hline & $\begin{array}{c}\text { Lag time } \\
(\min )\end{array}$ & $\begin{array}{c}\text { Rate of fibrillogenesis } \\
\left(1 \times 10^{-2} / \mathrm{min}\right)\end{array}$ & $\begin{array}{c}\text { Absorbance plateau } \\
(400 \mathrm{~nm})\end{array}$ \\
\hline Control & $5.1 \pm 0.2$ & $6.5 \pm 0.1$ & $0.34 \pm 0.08$ \\
TNX $(5 \mu \mathrm{g} / \mathrm{mL})$ & $5.5 \pm 0.1$ & $5.8 \pm 0.4$ & $0.34 \pm 0.04$ \\
TNX $(30 \mu \mathrm{g} / \mathrm{mL})$ & $6.6 \pm 0.4$ & $6.3 \pm 0.3$ & $0.35 \pm 0.01$ \\
BSA $(4.4 \mu \mathrm{g} / \mathrm{mL})$ & $6.6 \pm 0.4$ & $6.3 \pm 0.4$ & $0.34 \pm 0.07$ \\
Fibronectin $(16.7 \mu \mathrm{g} / \mathrm{mL})$ & $6.6 \pm 0.4$ & $6.2 \pm 0.2$ & $0.33 \pm 0.01$ \\
\hline
\end{tabular}




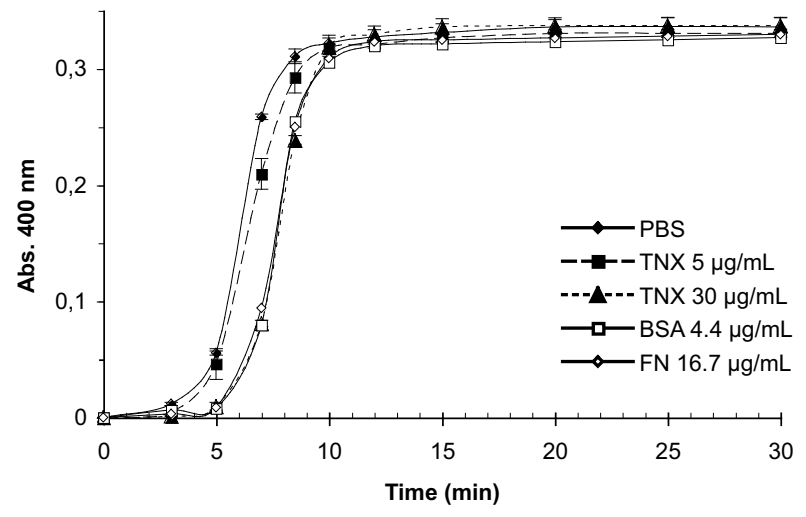

Figure 1 

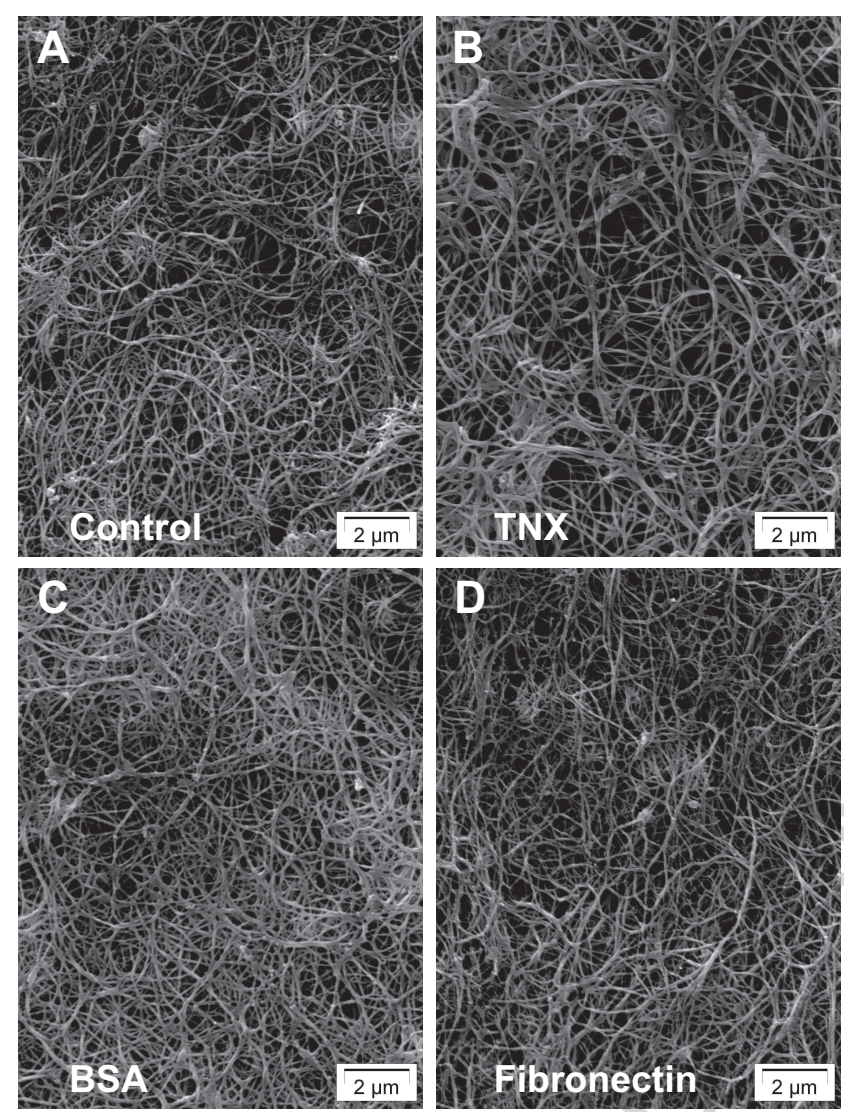

Figure 2 


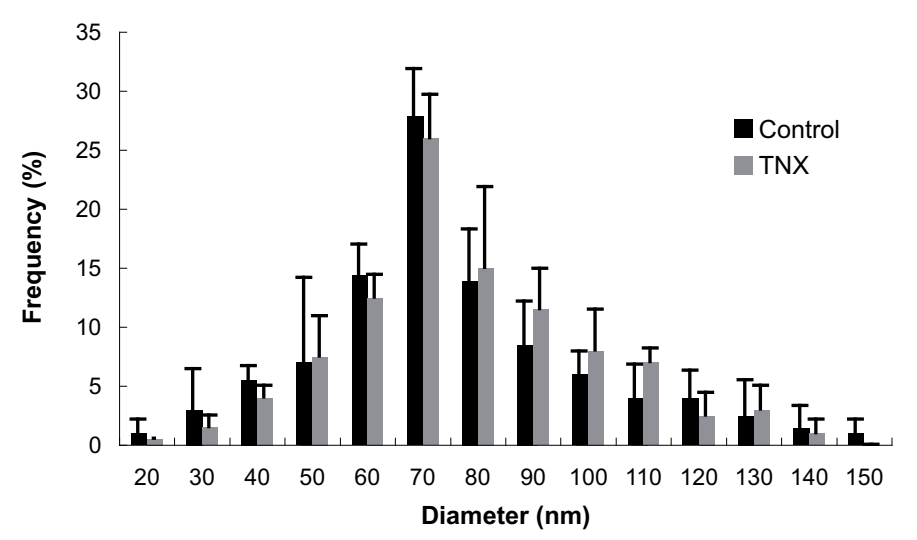

Figure 3 


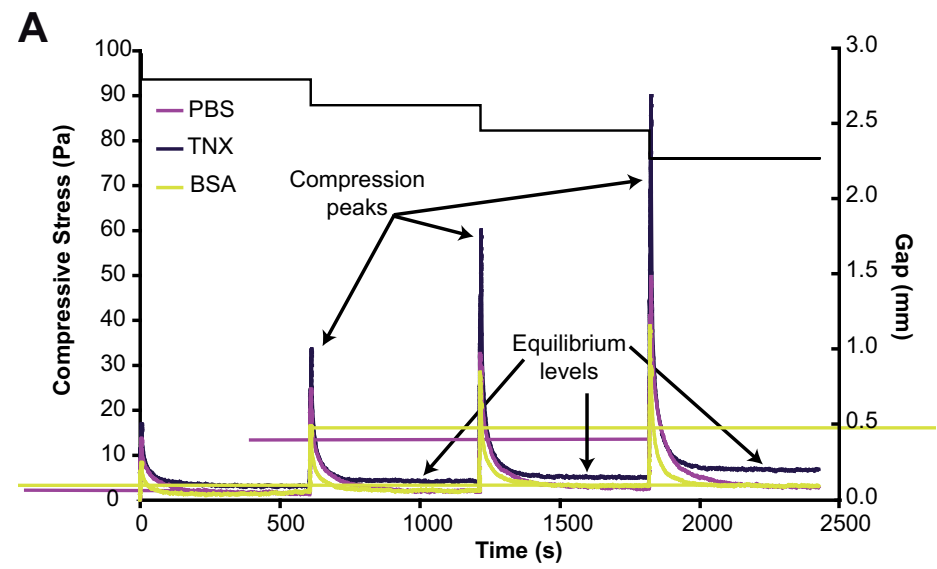

B

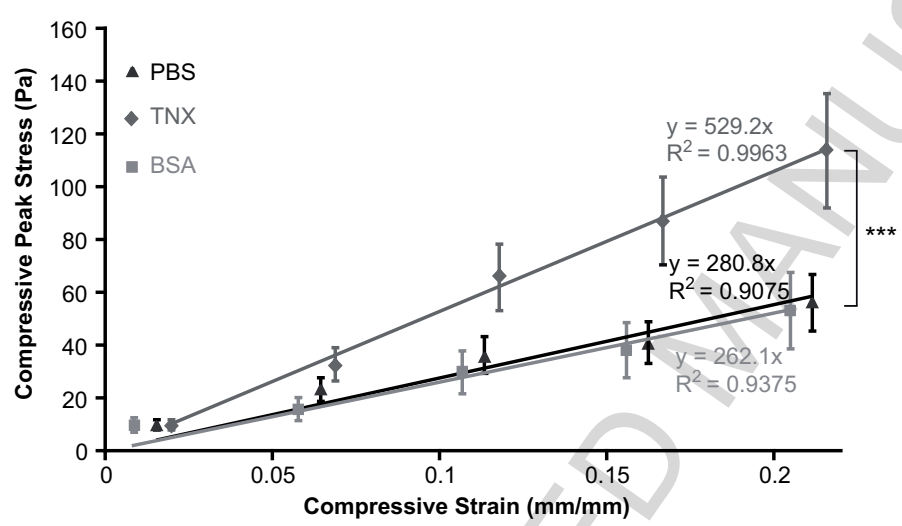

C

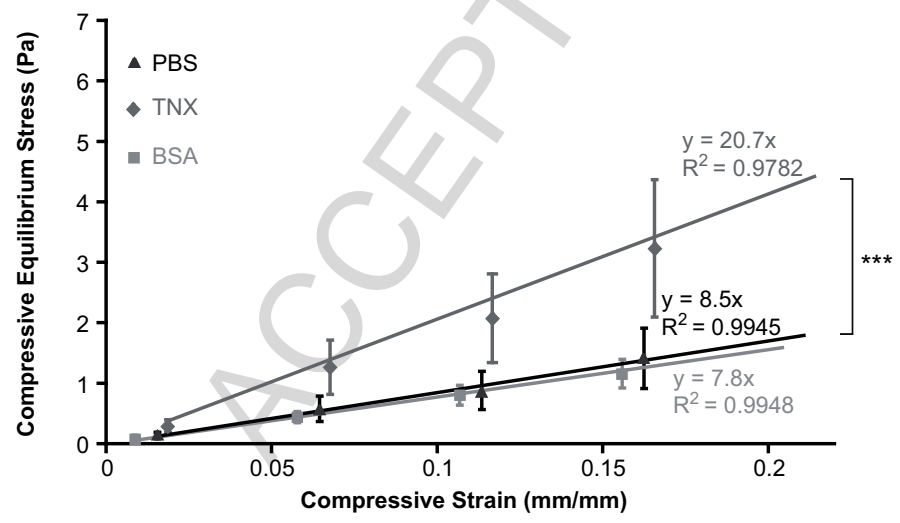

Figure 4 
DPBS DTNX $5 \mu \mathrm{g} / \mathrm{mL}$ 口TNX $15 \mu \mathrm{g} / \mathrm{mL}$ 口TNX $30 \mu \mathrm{g} / \mathrm{mL}$

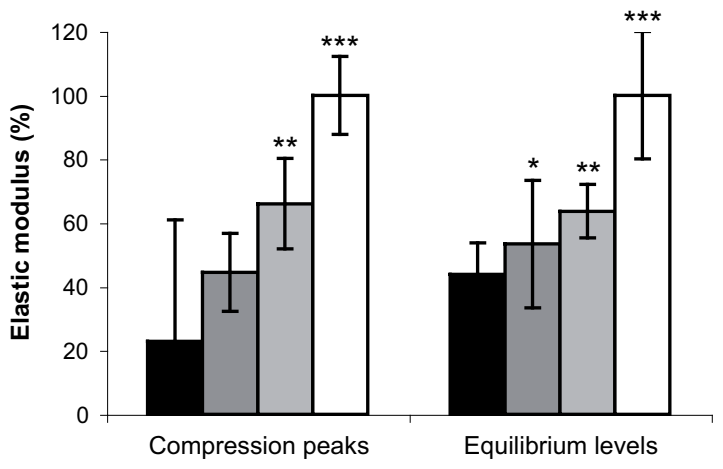

Figure 5 